\title{
PERSEPSI MASYARAKAT LOKAL TERHADAP USAHA TANI TANAMAN KARET PADA AREAL BEKAS PERLADANGAN DI DESA NYIIN KECAMATAN JELIMPO KABUPATEN LANDAK
}

\author{
(The Local Communities Perceptions About Rubber Cultivation On Swidden Used Areas In \\ Nyiin Village Sub District Jelimpo, Landak)
}

\author{
Erwin, Sofyan Zainal, Dirhamsyah \\ Fakultas KehutananUniversitas Tanjungpura Jalan Daya Nasional Pontianak 78124 \\ Email: erwinpabinuasilibong@ymail.com
}

\begin{abstract}
Rubber gives an important role for the national economy, in West Kalimantan, most of the population work as rubber farmers, especially the community in Nyiin Village, Jelimpo subdistrict, Landak district, is one of the villages that runs rubber plantations in the former cultivation area, which has been running since long time ago as the main livelihood to meet the needs of daily life. Some of the problems that are faced by rubber farmers, during the rainy season the rubber farmers have difficulty in tapping rubber, also falling rubber prices nowadays. This affects for the economy and the amount of rubber latex produced by the public. While the prices of basic food are rising, to deal with such a problem the community tends to look for side jobs, such as working in oil palm companies, mining gold, and other jobs. This situation naturally raises perceptions in the local community in Nyiin Village as rubber tappers. The aim of this study to find out the perception of the local community on rubber farming in the former cultivation area and analyze the relationship between knowledge, age and cosmopolitan factors with the perception of the local community on rubber farming in the former cultivation area. This research was carried out for 2 weeks effectively in the field, using descriptive and associative survey methods with interview techniques and questionnaire aids in the form that submitted to a number of respondents. of 81 respondents 73 respondents (90.12\%) had low perception, 8 respondents $(9.88 \%)$ had moderate perception and 0 respondents had low perception of rubber farming. It can be concluded that the people in Nyiin Village, Jelimpo sub-district, Landak district tend to have a low perception of rubber farming, this proves that the community feels the negative impact of the current rubber farming business, caused by the current low price of rubber.
\end{abstract}

Keywords: Communities, Perception, Rubber

PENDAHULUAN

Berdasarkan peraturan Menteri

Kehutanan Republik Indonesia Nomor :p.62/menhut-II/2011 Tentang pedoman pembangunan hutan tanaman berbagai jenis mengemukanan bahwa tanaman karet diperbolehkan menjadi salah satu tanaman pada Hutan Tanaman Industri. Jenis tanaman tahunan berkayu yang kayunya dapat dimanfaatkan untuk bahan baku industri dalam pembangunan hutan tanaman berbagai jenis antara lain meliputi karet, kelapa, dan/atau sawit serta dapat dikembangkan menjadi IUPHHBK-HT.

Komoditi karet telah memberikan kontribusi yang besar bagi perekonomian masyarakat lokal di Desa Nyiin. Beberapa masalah yang sering dihadapi oleh masyarakat yang mengusahakan usaha tani karet, yaitu ketika musim hujan tiba dimana 
masyarakat mengalami kesulitan dalam menyadap karet, dan ditambah lagi dengan menurunnya harga karet saat ini. Hal tersebut tentunya berpengaruh terhadap perekonomian dan jumlah produksi getah karet yang dihasilkan oleh masyarakat pada waktu-waktu tertentu, khususnya masyarakat lokal di Desa Nyiin yang mengandalkan usaha tani tanaman karet pada areal bekas perladangan sebagai mata pencaharian utama. Sedangkan harga sembako terus melonjak naik, untuk menghadapi persoalan demikian masyarakat terpaksa mencari pekerjaan alternatif, seperti bekerja di perusahaan sawit, menambang emas dan pekerjaan lainnya. Keadaan ini tentu saja menimbulkan persepsi dalam masyarakat lokal di Desa Nyiin selaku penyadap getah karet. Untuk mengetahui persepsi masyarakat terhadap usaha tani karet, maka perlu dilakukan penelitian mengenai persepsi masyarakat lokal terhadap usaha tani tanaman karet pada areal bekas perladangan. Penelitian ini bertujuan untuk mengetahui persepsi masyarakat lokal di Desa Nyiin Kecamatan Jelimpo Kabupaten Landak terhadap usaha tani tanaman karet pada areal bekas perladangan dan untuk menganalisis hubungan antara faktor pengetahuan, umur dan kosmopolitan dengan persepsi masyarakat lokal di Desa Nyiin terhadap usaha tani tanaman karet pada areal bekas perladangan.

Hasil penelitian ini diharapkan dapat menjadi bahan bacaan dan referensi bagi peneliti yang akan melakukan penelitian sejenis, dan memberikan informasi secara umum kepada masyarakat mengenai persepsi masyarakat lokal terhadap usaha tani tanaman karet pada areal bekas perladangan, dan memberikan masukan positif kepada pemerintah, khususnya pemerintah daerah untuk menyusun strategi dalam upaya peningkatan kemakmuran masyarakat lokal yang mengusahakan usaha tani karet untuk memenuhi kebutuhan mereka seharihari.

\section{METODE PENELITIAN}

Penelitian ini dilaksanakan di Desa Nyiin Kecamatan Jelimpo kabupaten Landak Kalimantan Barat dengan waktu selama 2 minggu efektif di lapangan. Objek penelitian ini adalah Desa Nyiin yang terdiri atas tiga dusun; Dusun Nyiin, Dusun Ugan dan Dusun Asam Mares, yang masyarakatnya bekerja sebagai penyadap getah karet. Adapun Alat-alat dalam penelitian ini meliputi, Kamera, Alat tulis, Kuesioner, Kalkulator.

Dalam pelaksanaan penelitian pengumpulan data dilakukan dengan teknik wawancara langsung yang diikuti dengan pengisian kuisioner oleh responden. Pengambilan sampel dilakukan dengan cara purposive sampling (pengambilan contoh secara sengaja), dimana sampel dipilih berdasarkan pertimbanganpertimbangan tertentu.

Untuk menentukan besarnya ukuran sampel dalam penelitian ini akan dihitung dengan rumus slovin 
(Riduwan, 2005) sebagai berikut: $\mathrm{n}=$

$$
\frac{\mathrm{N}}{1+\mathrm{Ne}^{2}}
$$

Keterangan :

$\mathrm{n}=$ Jumlah sampel

$\mathrm{N}=$ Jumlah populasi

$\mathrm{e}=$ Batas toleransi kesalahan (Persen

Kesalahan)

Diketahui jumlah populasi Desa Nyiin 441 KK dari tiga (3) dusun yaitu Dusun Nyiin 146 KK, Dusun Ugan 115 KK, dan Dusun Asam Mares 180 KK. Untuk uji validitas dan realibilitas diambil 15 KK dari $441 \mathrm{KK}$, jadi populasi yang dijadikan sampel sebanyak $426 \mathrm{KK}$, yaitu $141 \mathrm{KK}$ untuk Dusun Nyiin, 110 KK untuk Dusun Ugan dan 175 KK untuk Dusun Asam Mares. Persen kesalahan yang digunakan dalam rencana penelitian ini adalah $10 \%$. Artinya penelitian ini mempunyai tingkat ketelitian $90 \%$. Perhitungan untuk penentuan sampel dalam penelitian ini adalah :

$$
n=\frac{426}{1+426(0,1)^{2}}=\frac{426}{1+426(0,01)}=81 \mathrm{KK}
$$
menggunakan sampel sebanyak $81 \mathrm{KK}$, yang di ambil dari tiga (3) dusun diluar sampel yang digunakan untuk uji

\begin{tabular}{|c|c|c|c|}
\hline No & Nama Dusun & Jumlah KK & Jumlah Sampel \\
\hline 1 & Dusun Nyiin & $141 \mathrm{KK}$ & 27 \\
\hline 2 & Dusun Ugan & $110 \mathrm{KK}$ & 21 \\
\hline 3 & Dusun Asam Mares & $175 \mathrm{KK}$ & 33 \\
\hline \multicolumn{2}{|r|}{ Jumlah } & $426 \mathrm{KK}$ & 81 \\
\hline & $\begin{array}{l}\text { eristik populasi } \\
\text { ini meliputi : Kepala }\end{array}$ & $\begin{array}{ll}\text { dalam } & \mathrm{su} \\
\text { luarga } & \mathrm{ke}\end{array}$ & $\begin{array}{l}\text { ang banyak menyangkut } \\
\text { Im. }\end{array}$ \\
\hline
\end{tabular}
validitas dan realibilitas.

Tabel 1. Daftar Jumlah Populasi Sampel Penelitian untuk Kuesioner

yang berdomisili di Desa Nyiin yang bekerja sebagai penyadap getah karet, Lama berdomisili minimal lima (5) tahun danSehat jasmani dan rohani.

Penelitian ini menggunakan metode survey yang bersifat deskriptif dan asosiatif dengan teknik wawancara dan alat bantu kuesioner berupa formulir daftar pertanyaan yang diajukan kepada sejumlah responden. Menurut Kartono (1996), sebagaimana yang tercantum di dalam tulisan Haryani (2009), kuisioner diajukan untuk mendapatkan jawaban (tanggapan/respon) tertulis seperlunya guna menunjang penyelidikan mengenai

\section{Teknik Pengumpulan Data}

Teknik pengumpulan data di lakukan dengan teknik komunikasi langsung di bantu dengan alat berupa kuesioner yang berisikan rangkaian pertanyaan mengenai sesuatu hal terkait persepsi masyarakat lokal terhadap usaha tani tanaman karet pada areal bekas perladangan di Desa Nyiin Kecamatan Jelimpo Kabupaten Landak. Jawaban kuesioner umumnya telah disiapkan sehingga responden tinggal memilih salah satu jawaban yang dianggap tepat. Adapun data yang dikumpulkan meliputi data primer dan data sekunder.

\section{Variabel}


Variabel yang digunakan dalam penelitian ini dikelompokkan menjadi dua, yaitu variabel terikat dan veriabel bebas.

\section{Variabel Terikat;}

Persepsi masyarakat terhadap usaha tani tanaman karet yang dikelompokkan menjadi menjadi: Tinggi, Sedang dan Rendah.

\section{Variabel Bebas;}

Tingkat pengetahuan masyarakat terhadap usaha tani tanaman karet yang dikelompokkan menjadi: Tinggi, Sedang dan Rendah.

Umur adalah usia seseorang yang dihitung dari sejak lahir hingga saat sekarang yang dinyatakan dalam satuan tahun. Menurut Djojohadikusumo (1994) yang dikutip oleh Purwanto (2004), golongan yang lazim dianggap sebagai angkatan kerja produktif dalam masyarakat adalah mereka yang termasuk tingkat usia 15 - 64 tahun, dan dikelompokkan menjadi : muda jika berumur 15 -37 tahun, dewasa jika berumur $38-50$ tahun dan lanjut usia jika berumur $>50$ tahun.

Kosmopolitan masyarakat terhadap usaha tani tanaman karet yang dikelompokkan menjadi menjadi: Tinggi, Sedang dan Rendah.

\section{Uji Kuesioner}

Uji Validitas adalah suatu skala pengukuran harus valid agar dapat mengukur apa yang dimaksud untuk diukur (Soehartono, 1995). Uji validitas dilakukan agar dapat diperoleh derajad yang menggambarkan sejauh mana suatu instrumen dapat mencapai hasil pengukuran, sebagaimana yang di harapkan dengan tingkat ketelitian yang tinggi. Adapun jumlah responden yang digunakan dalam menguji kuisioner adalah $15 \mathrm{KK}$, jumlah tersebut diluar responden yang akan dijadikan sampel dalam penelitian ini. Teknik yang digunakan untuk mengetahui kesesuaian instrumen adalah teknik korelasi product moment yang dikemukakan oleh Pearson (Arikunto, S, 1993). Uji terhadap kuisioner untuk penelitian menggunakan rumus korelasi product moment dengan skala angka kasar, sedangkan nilai antara skorskor setiap belahan tes akan dicari dengan menggunakan rumus korelasi product moment yaitu sebagai berikut :

$$
r_{x y}=\frac{N\left(\sum x y\right)-\left(\sum x \cdot \sum y\right)}{\sqrt{\left\{N \sum x 2-\left(\sum x\right) 2,\left\{N \sum y 2-\left(\sum y\right) 2\right\}\right.}}
$$

Dimana :

$\mathrm{N} \quad=$ Jumlah Responden

$\mathrm{X}=$ Skor Pertanyaan Bilangan Genap

$\mathrm{Y}=$ =Skor Pertanyaan Bilangan Ganjil

rxy $=$ Koefesien Korelasi

Menurut Sangarimbun (1989), mengemukakan bahwa koefesien reabilitas yang sudah ditemukan harus dibandingkan dengan tabel nilai-nilai product moment. Taraf signifikan yang akan digunakan dalam hal ini adalah 5\%, maka alat penelitian dinyatakan valid.

Uji Reliabilitas adalah indeks yang menunjukkan sejauh mana suatu alat pengukuran dapat dipercaya atau dapat diandalkan, sehingga dengan uji iniakan diketahui tingkat konsistensi dari pengukuran yang dilakukan. Semakin besar jumlah item reliabilitas yang diperoleh akan semakin baik (Singarimbun, M, 1989).

Rumus yang dipakai untuk menguji reliabilitas kuisioner yang digunakan 
adalah rumus Sperman-Brown (Arikunto, $S, 1989)$, yaitu sebagai berikut :

$$
r_{11}=\frac{2 \cdot r \cdot 1 / 2 \cdot r \cdot 1 / 2}{(1+r \cdot 1 / 2 \cdot 1 / 2)}
$$

Dimana:

r1/2.1/2 = Korelasi product moment antara skor-skor antara belahan tes

r11 = Koefesien Reliabilitas

Nilai koefesien reliabilitas dapat dicari dengan menggunakan rumus korelasi product moment pada taraf signifikan yang digunakan yaitu $5 \%$.

\section{Teknik Pengolahan Data}

Data jawaban responden yang diperoleh dalam penelitian ini masih berupa data kualitatif, maka untuk itu terlebih dahulu harus ditransformasikan kedalam data kuantitatif, dimana untuk mengukur data tersebut digunakan Skala Likert. Dalam Skala Likert (Sumated Ratings Methode) terdapat pertanyaanpertanyaan, sehingga dalam menanggapi hal tersebut subjek memilih salah satu dari lima alternatif jawaban yang sesuai dengan keinginan subjek. Untuk pertanyaan yang bersifat tinggi diberi skor $a=5, b=4, c=3$, $\mathrm{d}=2$ dan $\mathrm{e}=1$. Sedangkan pertanyaan yang bersifat rendah diberi skor kebalikannya, kemudian skor-skor yang diperoleh tersebut dijumlahkan per variabel dan diambil rata-ratanya dengan ketentuan sebagai berikut : Kategori Tinggi (dengan skor > 3,5), Kategori Sedang (dengan skor 2,5 - 3,5), dan Kategori Rendah (dengan skor $<2,5)$.

Mengetahui persepsi masyarakat lokal terhadap usaha tani tanaman karet pada areal bekas perladangan di Desa Nyiin Kecamatan Jelimpo Kabupaten Landak, diberlakukan pengujian hipotesis dengan menggunakan rumus Chi-kuadrat. Menurut Sugiyono (2001), menyatakan bahwa pengujian hipotesis dengan satu variabel yang terdiri dari beberapa kategori dan sampel yang lebih dari 25 dapat dilakukan penelitian dengan menggunakan Chi-kuadrat $\left(X^{2}\right)$.

Rumus lengkap Chi-kuadrat $\left(X^{2}\right)$ adalah :

$X^{2}=\sum \frac{\{(f o-f t)\}}{f t}$

Dimana :

$X^{2}=$ Chi-kuadrat

$f 0=$ Frekuensi yang diperoleh

$f t=$ Frekuensi yang diharapkan

Sedangkan untuk mencari frekuensi yang diharapkan (ft) pada hipotesis deskriptif digunakan cara :

$f \mathrm{t}=\frac{\sum N}{\sum K}$

Dimana :

$f t=$ Frekuensi yang diharapkan

$\sum \mathrm{N}=$ Jumlah sampel

$\sum \mathrm{K}=$ Jumlah kategori

Bila $X^{2}$ hitung $>X^{2}$ tabel, maka hipotesis diterima. Dimana nilai tabel yang digunakan adalah signifikan 5\%.

Untuk menguji hipotesis hubungan antara variabel terikat (persepsi masyarakat lokal terhadap usaha tani tanaman karet pada areal bekas perladangan di Desa Nyiin Kecamatan Jelimpo Kabupaten Landak) dengan variabel bebas (pengetahuan, pendapatan, dan kosmopolitan) maka pengujiannya dapat menggunakan teknik statistik Chikuadrat. Rumus lengkap untuk Chikuadrat $\left(X^{2}\right)$ adalah sebagai berikut :

$X^{2}=\sum \frac{\{(f o-f t)\}}{f t}$ 
Dimana :

$X^{2}=$ Chi-kuadrat

$f 0=$ Frekuensi yang diperoleh

$f t=$ Frekuensi yang diharapkan

Sedangkan untuk mencari frekuensi yang diharapkan ( $f t)$ menurut Sumanto (1995) dalam Purwanto (2004) adalah :

$f \mathrm{t}=\frac{(\text { bixki) }}{N}$

Dimana :

$f t=$ Frekuensi yang diharapkan

bi= Jumlah baris

$\mathrm{ki}=$ Jumlah kolom

$\mathrm{N}=$ Total sampel

Bila $X^{2}$ hitung $>X^{2}$ tabel, maka hipotesis diterima. Dimana nilai tabel yang digunakan adalah signifikan 5\% dan $1 \%$.

\section{HASIL DAN PEMBAHASAN}

\section{Persepsi Masyarakat Lokal terhadap Usaha Tani Tanaman Karet}

Berdasarkan hasil analisis diperoleh nilai total $\chi^{2}$ hitung 118.7407 sedangkan nilai $\chi^{2}$ tabel dengan taraf signifikan $5 \%$, dan $\mathrm{db}=2$ adalah 41.748, dengan demikian berarti nilai total $\chi^{2}$ hitung $>\chi^{2}$ tabel, artinya hipotesis dapat diterima yang berarti dapat disimpulkan bahwa terdapat perbedaan frekuensi pada tingkat persepsi masyarakat terhadap usaha tani tanaman karet di Desa Nyiin.

Hasil penelitian menunjukan, bahwa 73 responden $(90,12 \%)$ cenderung mempunyai persepsi rendah terhadap usaha tani karet, 8 responden $(9,88 \%)$ cenderung mempunyai persepsi sedang terhadap usaha tani karet dan 0 responden cenderung mempunyai persepsi tinggi terhadap usaha tani karet di Desa Nyiin Kecamatan Jelimpo Kabupaten Landak, dari hasil interpretasi diatas, dapat disimpulkan bahwa masyarakat di Desa Nyiin cenderung mempunyai persepsi rendah terhadap usaha tani tanaman karet.

\section{Hubungan antara Faktor Pengetahuan dengan Persepsi Masyarakat Lokal terhadap Usaha Tani Tanaman Karet}

Berdasarkan hasil analisis diperoleh nilai total $\chi^{2}$ hitung 52.07407 sedangkan nilai $\chi^{2}$ tabel dengan taraf signifikan $5 \%$, dan $\mathrm{db}=2$ adalah 41.748, dengan demikian berarti nilai total $\chi^{2}$ hitung $>\chi^{2}$ tabel, artinya hipotesis dapat diterima yang berarti dapat disimpulkan bahwa terdapat perbedaan frekuensi pada tingkat persepsi masyarakat terhadap usaha tani tanaman karet di Desa Nyiin.

Berdasarkan hasil penelitian menunjukkan bahwa responden yang memiliki kategori tingkat pengetahuan tinggi 0 responden, sedang 53 responden $(65,43 \%)$ dan responden yang memiliki persepsi rendah 28 responden $(34,57 \%)$ terhadap usaha tani tanaman karet, dari hasil interpretasi diatas, dapat disimpulkan bahwa masyarakat di Desa Nyiin cenderung mempunyai pengetahuan sedang terhadap usaha tani tanaman karet. Dari hasil uji asosiatif juga didapatkan nilai $\chi^{2}$ hitung $>\chi^{2}$ tabel yaitu $16.802>$ 5.889 yang artinya tingkat pengetahuan memiliki pengaruh terhadap persepsi, dan didapat nilai koefisien hubungan $(\mathrm{C})=$ 0,38 yang bertarti tingkat pengetahuan berpengaruh posirtif terhadap persepsi dengan keeratan hubungan sebesar 38\%. Penelitian ini sesuai dengan pendapat Sueca et al (2001) yang menyatakan tingkat pengetahuan masyarakat tentang 
sesuatu berpengaruh terhadap persepsi dan perilakunya.

\section{Hubungan antara Faktor Kosmopolitan dengan Persepsi Masyarakat Lokal terhadap Usaha Tani Tanaman Karet}

Penelitian menunjukan bahwa 30 responden $\quad(37,04 \%) \quad$ cenderung mempunyai kosmopolitan rendah terhadap usaha tani karet, 43 responden $(53,09 \%)$ cenderung mempunyai kosmopolitan sedang terhadap usaha tani karet dan 0 responden cenderung mempunyai kosmopolitan tinggi terhadap usaha tani karet di Desa Nyiin. Hasil interpretasi diatas, dapat disimpulkan bahwa masyarakat di Desa Nyiin cenderung mempunyai kosmopolitan sedang terhadap usaha tani tanaman karet. Kemudian untuk mengetahui perbedaan frekuensi kosmopolitan masyarakat di Desa Nyiin terhadap usaha tani tanaman karet maka dilakukan uji chi-square deskriptif terhadap data kosmopolitan masyarakat. Berdasarkan hasil analisis Uji Chi-Square Deskriptif Kosmopolitan Masyarakat, maka diperoleh nilai total $\chi^{2}$ hitung 23.185 sedangkan nilai $\chi^{2}$ tabel dengan taraf signifikan 5\%, dan $\mathrm{db}=2$ adalah 41.748, dengan demikian berarti nilai total $\chi^{2}$ hitung $<\chi^{2}$ tabel, artinya hipotesis dapat ditolak yang berarti dapat disimpulkan bahwa tidak terdapat perbedaan frekuensi pada tingkat persepsi masyarakat terhadap usaha tani tanaman karet di Desa Nyiin.

Hasil penelitian ini terdapat hubungan antara tingkat komopolitan responden dengan persepsi masyarakat terhadap usaha tani tanaman karet di Desa Nyiin, karena $\chi^{2}$ hitung $>$ dari nilai $\chi_{\text {tabel dengan }}^{2}$ koefisien hubungan $(\mathrm{C})=0,680$ hal ini menunjukkan bahwa faktor kosmopolitan memberikan pengaruh positif kepada persepsi mayarakat terhadap usaha tani tanaman karet dengan keeratan hubungan sebesar 68\%. Semakin tinggi tingkat kosmopolitan masyarakat akan memiliki kecendrungan yang besar untuk dapat menerima suatu objek atau sesuatu hal yang bersifat membangun (Lestiana dalam Adha, 2010). Hasil penelitian ini sesuai dengan pendapat Budiono (2005) yang menyatakan kosmopolitan merupakan suatu wawasan dan pengetahuan yang luas.

4. Hubungan antara Faktor Umur dengan Persepsi Masyarakat Lokal terhadap Usaha Tani Tanaman Karet

Penelitian menunjukan bahwa 20 responden $\quad(24,69 \%) \quad$ cenderung mempunyai usia muda, 35 responden (43,21\%) cenderung mempunyai usia dewasa dan 26 responden $(32,1 \%)$ cenderung mempunyai usia tua. Dari hasil interpretasi diatas, dapat disimpulkan bahwa masyarakat di Desa Nyiin yang dijadikan responden dalam penelitian ini memiliki sebaran usia yang cukup merata di tiga kartegori.

Berdasarkan hasil analisis diperoleh nilai total $\chi^{2}$ hitung 4.222 sedangkan nilai $\chi^{2}$ tabel dengan taraf signifikan 5\%, dan $\mathrm{db}$ $=2$ adalah 41.748, dengan demikian berarti nilai total $\chi^{2}$ hitung $<\chi^{2}$ tabel, artinya hipotesis ditolak yang berarti tidak dapat disimpulkan bahwa terdapat perbedaan frekuensi pada tingkat usia masyarakat di Desa Nyiin.

Dalam penelitian ini 81 responden kita kelompokan ke dalam 3 kelompok 
usia yaitu muda, dewasa, dan tua. Dari ketiga kelompok ini semuanya cenderung memiliki persepsi rendah terhadap usaha tani karet. Hal ini disebabkan karena memang kurangnya pengetahuan masyarakat tentang keunggulan usaha tani karet, kemudian setelah dilakukan uji asosiatif pun didapat kesimpulan bahwa usia tidak berpengaruh terhadap persepsi, yang artinya semua kelompok usia memiliki persepsi yang sama terhadap usaha tani karet. Hal ini sejalan dengan penelitian Indra (2008) tentang persepsi, yang menyatakan bahwa tinggi rendahnya umur dalam suatu penelitian pada dasarnya tidak menentukan apakah individu responden mewakili pengetahuan yang lebih dan factor umur tidak menentuka sikap keterbukaan individu responden terhadap sesuatu yang baru.

\section{Kesimpulan}

Berdasarkan hasil analisis yang telah dilakukan dapat disimpulkan hal-hal sebagai berikut:

1. Masyarakat dalam penelitian ini adalah cenderung memiliki persepsi rendah yaitu dengan 73 responden $(90,12 \%)$ terhadap usaha tani tanaman karet di Desa Nyiin.

2. Berdasarkan hasil penelitian menunjukkan bahwa responden yang memiliki kategori tingkat pengetahuan sedang 53 responden $(65,43 \%)$ dan responden yang memiliki persepsi rendah 28 responden $(34,57 \%)$ terhadap usaha tani tanaman karet, dalam hal ini masyarakat cenderung memiliki pengetahuan sedang terhadap usaha tani karet di Desa Nyiin.
3. Berdasarkan penelitian ini 81 responden kita kelompokan ke dalam 3 kelompok usia yaitu muda, dewasa, dan tua. Dari ketiga kelompok ini semuanya cenderung memiliki persepsi rendah terhadap usaha tani karet.

4. Hasil penelitian ini diketahui bahwa responden dengan tingkat kosmopolitan tinggi sebanyak 8 responden, sedang 43 responden dan rendah 30 responden, dalam hal ini mayarakat cenderung memiliki persepsi sedang terhadap usaha tani tanaman karet di Desa Nyiin.

\section{Saran}

1. Diperlukan perhatian khusus dari pihak-pihak terkait dengan memperhatikan tingkat persepsi, pengetahuan, umur dan kosmopolitan pada masyarakat setempat dalam upaya meningkatkan persepsi masyarakat terhadap usaha tani karet di Desa Nyiin.

2. Masyarakat dengan kategori usia muda adalah generasi masa depan, karena itu jikalau ingin membentuk persepsi masyarakat yang selalu positif, maka kegiatan pembinaan atau kegiatan lainnya harus difokuskan dan melibatkan masyarakat dengan kategori usia muda ini.

3. Diperlukan penyuluhan-penyuluhan baik dari pemerintah daerah, pihak swasta maupun lembaga-lembaga tertentu, untuk memberikan pemahaman kepada masyarakat akan pentingnya usaha tani tanaman karet.

4. Bagi peneliti selanjutnya yang ingin mengetahui keterkaitan antara faktorfaktor yang mempengaruhi persepsi masyarakat terhadap usaha tani tanaman karet jangan hanya berfokus 
pada faktor pengetahuan, pendapatan dan kosmopolitan saja, misalnya bisa melihat faktor-faktor lain seperti luas lahan, harga komoditi karet, pembeli atau penampung, serta kemudahan dalam menanam, memelihara dan kemudahan dalam memasarkan komoditi karet sehingga hasil dari penelitian akan lebih valid.

\section{DAFTAR PUSTAKA}

Arikunto, Suharsimi. 1993. Prosedur Penelitian, Suatu Pendekatan Praktik. Jakarta. PT. Rineka Cipta

Budiono. 2005. Kamus Lengkap Bahasa Indonesia. Surabaya. Karya Agung Kartono. 1996. Psikologi untuk Manajemen Perusahaan Dan Industry, CV. Rajawali. Jakarta.
Riduwan. 2005. Belajar Mudah Penelitian Untuk Guru, Karyawan dan Peneliti Pemula, Bandung : Alfabeta.

Sangarimbun, M. 1989. Metode Penelitian Survey. Lp3s. Jakarta.

Soehartono, irawan. 1995. Metode Penelitian Sosial, PT. Remaja Rosdakarya. Bandung.

Sueca NP et al. 2001. Faktor-Faktor Derteminan Pengetahuan Dan Persepsi Masyarakat Tentang Bangunan Berlanggam Bali. Dimensi Teknik Arsitektur, Vol. 29, No 2

Sugiyono, 2001. Statistik Nonparametrik Untuk Penelitian, Alfabeta. Bandung. 